\title{
As conseqüências da nulidade de um tratado em Direito Internacional ${ }^{*}$
}

\author{
Júlia Knijnik Baumvol ${ }^{\dagger}$ \\ juliakb@free.fr
}

\begin{abstract}
RESUMO
O presente trabalho tem como objetivo principal contribuir com o estudo da nulidade dos tratados em Direito Internacional. O foco principal é a análise da Convenção de Viena de 1969 sobre o Direito dos Tratados e de seus trabalhos preparatórios, tendo em vista que a prática internacional nos dá poucos exemplos do estabelecimento de conseqüências jurídicas que resultam da nulidade de um tratado. De forma mais específica, é apresentada a problemática do tratamento que deve ser reservado aos atos realizados com base no tratado, antes de ser declarado nulo.
\end{abstract}

Palavras-chave: teoria dos tratados internacionais; nulidade em Direito Internacional; Convenção de Viena de 1969 sobre o Direito dos Tratados; Comissão do Direito Internacional (CDI).

\section{The Effects of the Nullity of a Treaty under International Law}

\section{ABSTRACT}

The purpose of the present work is to contribute to the discussion of the nullity of treaties under international law. The study has as main focus the 1969 Vienna Convention on the Law of the Treaties and its preparatory work, since international practice give us only few examples of the establishment of nullity's effects of a treaty. The main question addressed in this article concerns the treatment that is reserved for the acts that were eventually taken based on a treaty, before it was rendered void.

Key words: International Treaty Law Theory; Nullity under International Law; 1969 Vienna Convention on the law of the Treaties; International Law Commission (ILC).

\footnotetext{
* Texto traduzido do original em francês.

† Bacharel em Direito pela Universidade Panthéon-Assas Paris II; mestranda da Universidade Panthéon-Assas Paris II, em Direito Internacional Público. A autora agradece à professora Liba Juta Knijnik pelos comentários e pelas correções.
} 


\section{INTRODUÇÃO}

A nulidade de um ato é uma característica que retira seu valor jurídico, ou seja, ausenta as condições de conteúdo necessário à sua validade (SALMON, 2001, p.760). Segundo Salmon (2001, p. 414), as conseqüências jurídicas são, mais especificamente, o conjunto de efeitos que resultam de um ato ou de um fato jurídico. Assim, este estudo tem por objetivo analisar as conseqüências jurídicas que resultam de um tratado que não possui valor jurídico em razão da ausência de conteúdo necessário à sua validade. Neste trabalho, será analisado, mais especificamente, o artigo 69 da Convenção de Viena de 1969 sobre o Direito dos Tratados, que codificou o direito costumeiro na matéria ${ }^{3}$.

É importante destacar que, mesmo sendo a nulidade inerente a todo sistema jurídico, essa é uma sanção mal adaptada à ordem jurídica internacional e, portanto, difícil de ser implementada. A doutrina, mais precisamente os autores Weil (1992, p. 315), Cahier (1972, p. 685) e Combacau (1991, p. 195) vêem esse conceito de nulidade ligado à ordem jurídica interna e, como tal, inapta a ser transplantada a sistemas como o direito internacional, ou seja:

"um conceito não pode pretender a um tal estatuto em um sistema de direito onde a realidade dos seres legais é atestada pelo testemunho que oferecem individualmente os Estados e onde esses retiram em definitivo a sua existência a partir de atos concordantes, que nas suas relações mútuas decidem reconhecer". ${ }^{4}$

Desse modo, verifica-se um caráter artificial no ato de transposição puro e simples de noções jurídicas internas para o direito internacional. Fica claro que, apesar de grande elaboração da parte da Comissão do Direito Internacional (CDI) e de uma doutrina abundante, a nulidade dos tratados permanece uma matéria extremamente teórica. A prática internacional dá-nos poucos exemplos de casos em que o problema da validade dos tratados nos é apresentado. Os tribunais pronunciam raramente a nulidade de uma disposição convencional, e apenas as opiniões individuais anexas às sentenças empenham-se nesse terreno.

\footnotetext{
${ }^{3}$ Assim sendo, exclui-se o estudo do jus cogens, previsto no artigo 71 da mesma Convenção.

${ }^{4}$ Do original, « un concept ne peut prétendre à un tel statut dans un système de droit où la réalité des être légaux n'est attestée que par le témoignage qu'en donnent individuellement les Etats et où ils ne tiennent en définitive leur existence que des actes concordants par lesquels dans leurs rapports mutuels, ceux-ci veulent bien la leur reconnaître ». (COMBACAU, 1991. p.196)
} 
Em direito internacional, como bem indica Weil (1992, p. 327), “em todos os lugares (a nulidade) cede lugar a mecanismos de substituição que podem parecer-se em alguns aspectos à nulidade, mas que não são verdadeiramente nulidade”. Pode-se citar como exemplo a decisão Libia/Tchád de 3 de fevereiro de 1994, em que foi estabelecido um Estado não poder defender-se, pela sua inexperiência diplomática, para justificar um erro e obter a nulidade de um tratado. Nesse caso, a nulidade não foi declarada, mas a Corte Internacional de Justiça (CIJ) tomou em consideração a "falta de experiência para realizar negociações difíceis" e o "desconhecimento de fatos pertinentes ao caso" para interpretar o tratado 5 . Mais uma vez, a nulidade escapou às mãos da CIJ, que, entretanto, estabeleceu efeitos inesperados com base no pedido das partes.

Verifica-se que a declaração de nulidade de um tratado é um fato raro e, quando ocorre, os tribunais não examinam, exatamente, as conseqüências decorrentes dessa declaração, pelo menos não de forma clara, tal qual estabelecido pelo artigo 69 da Convenção de Viena. A questão central em relação às conseqüências da declaração de nulidade dos tratados é a de compreender, muito além da questão da ausência de força jurídica do tratado por si só, objeto da primeira parte deste estudo, qual destino é reservado aos atos que foram realizados com base na aplicação desse instrumento declarado nulo, a discussão da segunda parte do artigo.

A estrutura deste estudo tem como principal objetivo trazer à luz a essência do texto da Convenção de Viena e de seus trabalhos preparatórios. Todavia, antes de discutir o cerne do tema, cabe ressaltar que uma parte da doutrina sobre a matéria realiza distinção entre as nulidades “absolutas” e “relativas”. Essa distinção não será utilizada, porque, como indica Ago (1963, p. 249) no anuário da CDI, “do ponto de vista das conseqüências, não há diferença entre nulidade absoluta ou relativa”. De acordo com a leitura do artigo $69 \S 1^{\circ}$ da Convenção de Viena, pode-se constatar que essa distinção não faz parte do espírito do texto, sendo apenas uma distinção doutrinária sem relevância para a presente análise.

\footnotetext{
${ }^{5}$ Différend territorial (Jamahiriya arabe libienne c. Tchád), 1994. Recueil C.I.J.
} 


\section{AS CONSEQÜÊNCIAS DA NULIDADE DE UM TRATADO - O ARTIGO $69 \S 1^{\circ}$ DA CONVENÇÃO DE VIENA DE 1969}

Segundo o artigo $69 \S 1^{\circ}$ da Convenção de Viena, "É nulo um tratado cuja nulidade resulta das disposições da presente Convenção. As disposições de um tratado nulo não têm eficácia jurídica”. Com base neste artigo, é possível afirmar, por um lado, que a essência da nulidade é a ausência de força jurídica do ato declarado nulo e, por outro, que as conseqüências da nulidade de um tratado são retroativos.

\subsection{A essência da nulidade: a ausência de força jurídica de um tratado}

A conseqüência principal da nulidade de um tratado é que nenhum Estado pode valer-se de um tratado declarado nulo. A Convenção de Viena é clara quanto à matéria no artigo $69 \S 1^{\circ}$. Na segunda frase: “As disposições de um tratado nulo não têm eficácia jurídica”, impõe-se que, quando a nulidade é estabelecida, o tratado torna-se inoponível aos outros Estados, independentemente de quem sejam e, reciprocamente, esses não podem dar ao tratado efeitos jurídicos. A conseqüência direta disso, como explica Verhoeven (1980, p.88), é “ (que) o resultado buscado pelo autor do ato nulo não será atingido (...) Assim, uma sentença não tira o direito entre as partes, uma ocupação não conferirá um título de soberania, um pedido não acionará a C.I.J. (...)”. 6

Todavia, a segunda parte do artigo não proporciona solução completa do problema. A questão que permanece é saber se, uma vez o tratado declarado nulo, as conseqüências da declaração de nulidade são anteriores ou posteriores à anulação.

\subsection{A retroatividade das conseqüências, prevista no artigo $69 \S 1^{\circ}$ da Convenção de Viena de 1969}

A retroatividade é o caráter de um fato ou de uma norma que produz efeitos jurídicos a uma data anterior à sua realização (por um fato) ou à sua entrada em vigor (por uma norma) (SALMON, 2001, p. 1009). O princípio geral em direito internacional público é

\footnotetext{
${ }^{6}$ Do original, « (qu'il) ne soit pas atteint le résultat poursuivi par l'auteur de l'acte nul (....). Ainsi, une sentence ne dia-t-elle le droit entre les parties, l'occupation ne conféra-t-elle pas de titre de souveraineté, la requête ne saisira pas la C.I.J (...)».
} 
o da não-retroatividade dos atos. O artigo 28 da Convenção de Viena dispõe que “a não ser que uma intenção diferente se evidencie do tratado, ou seja, estabelecida de outra forma, suas disposições não obrigam uma parte em relação a um ato ou fato anterior ou a uma situação que deixou de existir antes da entrada em vigor do tratado, em relação a essa parte”. Isto significa que a aplicação de uma norma a situações ou fatos ocorridos antes de sua entrada em vigor é excluída, salvo indicação contrária do autor da norma. A implementação dessa nãoretroatividade de princípio, “é comandada pela preocupação de conciliar dois objetivos às vezes contraditórios: garantir a segurança jurídica dos destinatários das normas internacionais e não atrasar inutilmente a aplicação de novas regras de direito internacional.”7

No que diz respeito ao artigo $69 \S 1^{\circ}$ da Convenção de Viena, não se pode afirmar, com simples leitura, que o texto contenha indicações normativas expressas ou implícitas que revogam o princípio de não-retroatividade ${ }^{8}$. Entretanto, com base na leitura dos trabalhos preparatórios da Convenção de Viena, vê-se que a intenção dos autores foi estabelecer um princípio geral de retroatividade. O relatório da CDI à Assembléia Geral da ONU em 1966 não deixou nenhuma dúvida quanto ao assunto, pois considera que "se é trazida uma prova da nulidade de um tratado por qualquer uma das razões enumeradas, isto significa que o tratado é nulo ab initio e não simplesmente a partir da data na qual a causa da nulidade foi invocada". ${ }^{9}$ Em seguida, a CDI afirma que “a fim de não subsistir nenhuma dúvida sobre este ponto, o parágrafo $1^{\circ}$ do presente artigo estipula que as disposições de um tratado nulo não possuem força jurídica”. ${ }^{10}$

Segundo Bindschedler-Robert (1968, p. 195), a anulação retroativa significa que os Estados (inclusive os Estados terceiros desde que isso não afete os seus direitos existentes) devem, a partir do momento em que a nulidade é declarada, comportar-se como se todos os

\footnotetext{
${ }^{7}$ Do original, « est commandée par le souci de concilier deux objectifs parfois contradictoires : garantir la sécurité juridique des destinataires des normes internationales et ne pas retarder indûment l'application des règles nouvelles de droit international ». (PELLET; DAILLIER, 2001. p. 219)

${ }^{8}$ A C.I.J., no caso Ambatielos, decidiu que o princípio de não-retroatividade « aurait pu être contredit s’il avait existé une clause ou une raison particulière appelant une interprétation rétroactive » (Caso Ambatielos, Recueil C.I.J., 1952, p. 40). Esta decisão não afirma qual derrogação pode servir de base à exceção implícita. A C.P.I.J., entretanto, admitiu que a derrogação implícita à não-retroatividade poderia resultar do objeto do tratado em questão (Caso Mavrommatis, 1924, Recueil C.P.I.J., série A, n²2, p. 24).

9 Do original, «La Commission a estimé que, si l'on rapporte la preuve de la nullité d'un traité pour l'une quelconque des causes énumérées, cela signifie que le traité est nul ab initio et non pas simplement à partir de la date à laquelle la cause de nullité a été invoquée (...). (NATIONS UNIES, 1966, p. 288).

${ }^{10}$ Do original, "Afin de ne laisser subsister aucun doute sur ce point, le paragraphe 1 du présent article stipule simplement que les dispositions d'un traité nul n'ont pas de force juridique ». (NATIONS UNIES, 1966, p. 288).
} 
atos anulados sempre tivessem sido nulos. Há, desse modo, um retorno ao statuo quo ante de uma maneira integral.

A questão que resta é a de saber qual tratamento deve ser reservado aos atos que foram realizados com base no tratado, antes de ser declarado nulo. Serão examinadas, na segunda parte deste estudo, as três soluções para essa questão, apresentadas nos parágrafos $2^{\circ}$, $3^{\circ}$ e $4^{\circ}$ do artigo 69 da Convenção de Viena de 1969.

\section{AS CONSEQÜENNCIAS DA NULIDADE SOB OS ATOS REALIZADOS COM BASE EM UM TRATADO NULO}

Podem-se analisar essas conseqüências sob três dimensões diferentes: temporis, personae e materiae.

\subsection{As conseqüências temporais da nulidade de um tratado}

Se o princípio estabelecido pela Convenção de Viena, como indica a primeira parte deste estudo, é o da nulidade $a b$ initio ou ex tunc, constata-se que o princípio de retroatividade é atenuado pela possibilidade de estabelecer, em alguns casos, a nulidade ex nunc.

\subsubsection{O princípio da nulidade ex tunc}

\subsubsection{Um princípio que é raro na prática}

A conseqüência direta da nulidade $a b$ initio estabelecida com base no artigo $69 \S$ $1^{\circ}$ da Convenção de Viena é que, se algum ato é realizado em execução a esse ato nulo, antes da constatação de nulidade, as partes devem restabelecer, nas suas relações, a situação que haveria existido se esses atos não tivessem sido realizados. Esse retorno ao statuo quo integral traz conseqüências sérias para o direito internacional e é por esta razão que o pedido de anulação retroativa diante do juiz internacional é raro. Na verdade, o que interessa ao 
requerente de um litígio internacional é a cessação da situação ilícita e a indenização dos danos sofridos. Nesse sentido, explica Bindschedler-Robert (1968, p. 198):

"normalmente é suficiente, neste sentido, constatar a situação de direito que condiciona a regra de comportamento ou do ato ilícito. Ou ele (o Estado) pode requerer que o demandado seja condenado a efetuar algumas prestações, mas em geral há pouco interesse a que uma anulação seja retroativa, mesmo se for uma medida de direito interno". ${ }^{11}$

É, sobretudo, nos tratados de paz que se podem encontrar casos de anulação retroativa de atos jurídicos internacionais considerados como ilícitos. Como exemplo, ressalta-se o artigo 35 do tratado de paz de 1947, onde a Itália reconhece a validade de todas as medidas que a Etiópia tomou ou tomará no futuro, em vista de anular as medidas tomadas pela Itália em relação à Etiópia, o que certamente cobre a anulação retroativa. ${ }^{12}$.

\subsubsection{A implementação da retroatividade de princípio}

A retroatividade como regra está disposta no artigo $69 \S 3^{\circ}$ da Convenção de Viena: "Nos casos previstos pelos artigos 49 (dolo), 50 (corrupção de um representante do Estado), 51 (coação de representante de um Estado) ou 52 (coação de um Estado pela ameaça ou emprego da força), o parágrafo 2 não se aplica (...)”. Em todos esses casos (elencados de forma limitativa), a nulidade, uma vez declarada, será obrigatoriamente $a b$ initio. Parece ser lógico não permitir a um Estado que viciou um tratado beneficiar-se de uma cláusula que, como será visto no caso do parágrafo $2^{\circ}$, poderia atenuar as conseqüências da nulidade. A CDI, no relatório de 1966, afirma de forma clara, porém sem muitas justificações, que "por motivos evidentes, o $\S 3^{\circ}$ priva das avantagens previstas no $\S 2^{\circ}{ }^{13}$ Mesmo que alguns autores condenem o caráter penal dessa disposição ${ }^{14}$, este estudo segue o pensamento de

${ }^{11}$ Do original, « il lui suffira même souvent, dans ce but, de faire constater la situation de droit qui conditionne la règle de comportement, ou l'acte illicite. Ou bien il demandera que le défendeur soit condamné à accomplir certaines prestations, mais en général il n'aura que peu d'intérêt à une annulation rétroactive, même s'il s'agit d'une mesure de droit interne ».

${ }^{12}$ A questão é bem explicada por Bindschedler-Robert (1968, p. 197).

${ }^{13}$ Do original, «pour des raisons évidentes, le $\S 3$ prive des avantages prévus par le $\S 2$ ».(NATIONS UNIES, 1966, p. 288).

${ }^{14}$ Mais precisamente Bindschedler-Robert (1968, p. 190). 
Verhoeven (1980, p.93): “ao invés de representar uma política repressora, esta disposição parece testemunhar a preocupação de não favorecer a má-fé”. 15

Constata-se, entretanto, no que diz respeito ao princípio da retroatividade, que, na prática diplomática, os Estados não se satisfazem com solução tão distinta que possa apresentar inconvenientes para ambas as partes em um litígio internacional. A melhor ilustração disso é o Acordo germano-tchecoslováquio de 19 de junho de 1973, que, no preâmbulo, apresenta: "reconhecendo que o acordo de Munich de 29 de setembro de 1938 foi imposto à República Tchecoslováquia, sob o emprego da força pelo regime nazista”. O que interessa para este estudo é que, nesse acordo, os dois governos preferiram não precisar a qual data remonta a nulidade do acordo de Munich. Conforme o artigo primeiro do tratado de 1973, a RFA e a Tchecoslováquia consideraram como “nulo, nas condições do presente tratado, o acordo de Munich de 29 de setembro de 1938, no que toca às relações entre os dois países”. O artigo $2^{\circ}$ do mesmo acordo indica que o tratado "não afeta as conseqüências jurídicas que emanam para as pessoas físicas ou morais de direito que estiveram em vigor no período de 30 de setembro de 1938 a 9 de maio de 1945”. Uma exceção é feita, entretanto, na hipótese de que essas conseqüências sejam incompatíveis com os princípios fundamentais da justiça (BRETTON, 1973. p. 192-193).

\subsubsection{As controvérsias doutrinais sobre a retroatividade de princípio}

A doutrina sobre a matéria pergunta se essa retroatividade de princípio é realista e coerente. Como constata Verhoeven (1980, p. 90),

"há uma certa ingenuidade em afirmar uma retroatividade de princípio que, nos fatos, possui poucas chances de ser algum dia respeitada. É pedir demais a um direito que, subordinado ao peso da efetividade, não consegue de jeito nenhum impor as nulidades, quanto mais impor a fiç̧ão da retroatividade"16.

É possível perguntar se, ao invés de estabelecer uma regra geral como a do artigo 69 da Convenção de Viena, não seria melhor analisar as circunstâncias de cada caso para

\footnotetext{
${ }^{15}$ Do original, "plutôt qu'une politique de répression, elle paraît toutefois témoigner d'un soucis de ne pas favoriser la mauvaise foi ».

${ }^{16}$ Do original, «Il y a partant quelque naïveté à affirmer une rétroactivité de principe qui, dans les faits, a peu de chances d'être jamais respectée. C'est trop demander sans doute à un droit qui, courbé sous le poids d'effectivité, ne réussit guère à imposer des nullités, que lui demander aussi d'imposer les fictions de la rétroactivité ».
} 
estabelecer a retroatividade de princípio. Isso se justificaria pelo fato de que a gravidade do dano varia em cada caso, e a retroatividade de princípio pode mostrar-se perigosa.

\subsubsection{As atenuações do princípio: a nulidade ex nunc}

\subsubsection{O significado do artigo 69 § $2^{\circ}$, alíneas “a” e “b” da Convenção de Viena de 1969}

São as alíneas “a” e “b” do parágrafo $2^{\circ}$ do artigo 69 da Convenção de Viena que dão as diretrizes para atenuar a retroatividade de princípio. Segundo esse parágrafo, se tiverem sido praticados atos em virtude desse tratado:

a) cada parte pode exigir de qualquer outra parte o estabelecimento, na medida do possível, em suas relações mútuas, da situação que teria existido se esses atos não tivessem sido praticados;

b) os atos praticados de boa fé, antes de a nulidade haver sido invocada, não serão tornados ilegais pelo simples motivo da nulidade do tratado.

A fim de explicar essas disposições, a CDI, no relatório de 1966, indica que:

"Bem que o tratado tenha sido atingido de uma nulidade $a b$ initio, pode acontecer que, por razões perfeitamente legítimas, as partes invoquem a causa desta nulidade que, após ter durante algum tempo agido de boa fé sob fundamento do tratado, como se esse fosse completamente válido"17.

Seria legítimo atenuar o rigor de uma sanção retroativa a fim de reduzir as perturbações criadas pelo retorno dos atos ao ponto inicial.

Mais precisamente, a CDI considerou, no relatório de 1966, que:

"se a causa da nulidade não se acompanhar de nenhum ato delituoso que tenha por autor uma das partes (isto é, na ausência de dolo, corrupção ou ameaça imputável a uma das partes), deve-se levar em conta, para

${ }^{17}$ Do original, «Bien que le traité soit atteint d'une nullité ab initio, il se peut que, pour des raisons parfaitement légitimes, les parties n'invoquent la cause de cette nullité qu'après avoir, durant un certain temps, agi de bonne foi en s'appuyant sur le traité, comme si celui-ci était entièrement valable ». (NATIONS UNIES, 1966, p. 288). 
determinar a situação jurídica da questão, não somente a nulidade $a b$ initio mas também a boa fé das partes”18.

Assim, o $\S 2^{\circ}$ do artigo 69 da Convenção de Viena atenua a retroatividade de princípio. É importante ressaltar que a atenuação é aplicada apenas aos casos que não foram excluídos pelo artigo $69 \S 3^{\circ}$, ou seja, afora o dolo, a corrupção e a ameaça. Uma vez estabelecido o contexto do artigo, falta estudar o seu alcance.

\subsubsection{0 alcance da nulidade ex nunc: o que as alíneas “a” e "b" do artigo $69 \S 2^{\circ}$ querem dizer}

Segundo a alínea “a” do artigo 69 parágrafo $2^{\circ}$ da Convenção de Viena, se alguns atos foram realizados com base em um tratado declarado nulo, qualquer Estado-parte pode pedir a qualquer outro Estado também parte que estabeleça, tanto quanto for possível, nas relações mútuas, a situação que teria existido se tais atos não tivessem sido realizados. Em resumo, este texto reconhece que, em princípio, a anulação de um tratado, a contar da data de sua conclusão, deve ter pleno efeito e que, por conseqüência, toda e qualquer parte ao tratado pode requerer que o statuo quo seja restabelecido na medida do possível.

Da leitura da alínea referida decorrem três conclusões principais. Primeiramente, com base na expressão "na medida do possível”, ocorre, de acordo com Pellet (2001, p.220), o ápice da atenuação da retroatividade de princípio, pois a Convenção de Viena parece admitir às partes, se elas estiverem de acordo, a possibilidade de considerar o tratado nulo apenas para o futuro das suas relações. Em segundo lugar, a Convenção oferece às partes a faculdade de pedir o retorno da situação anterior. Isto significa, a contrario, que a disposição não impõe o dever de pedir o reestabelecimento do statuo quo ante (VERHOEVEN, 1979/1980. p. 92). Em terceiro lugar, a disposição não obriga a continuidade de um pedido de nulidade formulado.

Com base nessas três conclusões, pode-se perguntar, assim como uma parte da doutrina o fez, se a alínea "a” de exceção não faz desaparecer a regra de retroatividade ou se essa regra tornou-se a exceção. Em efeito, constata-se que a aplicação da retroatividade é deixada à inteira discrição das partes lesadas e, ademais, é subordinada, em cada caso, à

${ }^{18}$ Do original, «si la cause de nullité ne s'accompagne d'aucun acte délictueux qui ait pour auteur l'une ou l'autre des parties (c'est-à-dire, en l'absence de dol, corruption, ou contrainte imputables à l'une ou l'autre partie), il y avait lieu de tenir compte, pour déterminer quelle est la situation en droit, )à la fois de la nullité du traité ab initio et de la bonne foi des partie ». (NATIONS UNIES, 1966, p. 288). 
interpretação da expressão “na medida do possível”, o que não deixa de provocar dificuldades para a prática internacional.

Segundo a alínea “b” do artigo 69 parágrafo $2^{\circ}$ da Convenção de Viena, se alguns atos foram realizados com base em um tratado declarado nulo, os atos realizados com boa-fé, antes que a nulidade tenha sido invocada, não são tornados ilícitos do simples fato da nulidade do tratado. Assim, a alínea proporciona às partes a segurança de que os atos realizados de boa-fé, com base no tratado, não se transformarão em atos ilícitos, uma vez que o tratado foi declarado nulo. Ao utilizar a expressão “do simples fato da nulidade do tratado”, a CDI indica claramente que "se o ato em questão é ilícito por qualquer outra razão, independentemente da nulidade do tratado, o parágrafo em questão não é em si suficiente para torná-lo ilícito”19.

Em síntese, algumas conclusões podem ser retiradas do artigo $69 \S 2$ “a” e "b”, mas isto não significa que todos os problemas relativos à redação desse texto tenham sido resolvidos. Outros problemas restam para ser analisados.

\subsubsection{Os problemas provocados pela nulidade ex nunc: o que as alíneas “a” e "b" do artigo 69 § $2^{\circ}$ não significam}

O que se pode constatar da leitura das alíneas “a” e “b” do artigo $69 \S 22^{\circ}$ é a mistura de problemas de nulidade - falta objetiva de validade - e de responsabilidade análise objetiva de um ato delituoso válido ou nulo. Se, de um lado, a alínea "a” é formulada por meio de restitituo in integrum, que é o modo elementar de reparação de um dano, de um outro, a alínea “b” refere-se à noção de “lícito”.

Como bem indica a doutrina ${ }^{20}$, o que essas alíneas confundem é a dimensão temporal da nulidade e os modos de reparação de um ato ilícito. Efetivamente, um aspecto é a retroatividade da nulidade, e outro é estabelecer a responsabilidade ligada aos atos declarados nulos, mesmo que de modo retroativo. A CDI, nos trabalhos preparatórios da Convenção de Viena, trouxe uma resposta definitiva ao problema, afirmando, em relação ao artigo $69 \S 2^{\circ}$ :

\footnotetext{
${ }^{19}$ Do original, si l'acte en question est illicite pour toute autre raison, indépendamment de la nullité du traité, le paragraphe en question ne suffit pas à le rendre illicite. (NATIONS UNIES, 1996, p. 289).

${ }^{20}$ Mais precisamente, VERHOEVEN, J. Les nullités du droit des gens. In : Droit international 1: Institut des hautes études internationales de Paris: cours et travaux. Paris : Pedone, 1979/1980. p. 104 e BINDSCHEDLER-ROBERT, D. De la rétroactivité en droit international public. In: Recueil d'études de droit international en hommage à Paul Guggenheim, Université de Genève, Institut universitaire des hautes études internationales, Paris: Pedone, 1968. p. 184-200.
} 
"O presente artigo trata apenas das conseqüências jurídicas da nulidade de um tratado. Ele não trata de nenhuma questão de responsabilidade ou de reparação que emana de atos que são a causa da nulidade de um tratado. $\mathrm{O}$ dolo e a ameaça, por exemplo, podem levar a questões tanto de responsabilidade e reparação como de nulidade. Mas essas questões são excluídas do campo de aplicação dos presentes artigos pela regra do artigo $69^{\prime 21}$.

Assim, mesmo se o texto aparenta ser confuso, deve-se excluir, na sua aplicação, toda e qualquer questão relativa à responsabilidade. O que é importante ressaltar em relação a este artigo é que a nulidade $a b$ initio aparenta ser um princípio mais na esfera téorica do que na prática internacional, em que aparenta ser a exceção. Uma vez vista a dimensão temporal da nulidade, serão estudadas as dimensões em relação às pessoas e à matéria.

\subsection{O efeito da nulidade em relação às partes do tratado}

Como bem explica Pellet e Daillier (2001, p. 213), quando a nulidade de um tratado bilateral é admitida, o tratado no seu conjunto ou as disposições que são atingidas pela nulidade cessam de apresentar efeitos em relação às partes nas condições que foram descritas anteriormente. O problema é muito mais complexo no caso de um tratado multilateral. A nulidade não produz necessariamente as mesmas conseqüências em relação ao Estado em que o consentimento foi viciado e em relação aos outros Estados que também são partes do tratado. A solução do problema é dada pelo princípio de que a nulidade não possui efeitos além dos sujeitos anteriormente obrigados pelo ato declarado nulo. Isso é recordado pela Convenção de Viena no parágrafo $4^{\circ}$ do artigo 69, que dispõe: “No caso da nulidade do consentimento de um determinado Estado em obrigar-se por um tratado multilateral, aplicamse as regras acima nas relações entre esse Estado e as partes no tratado”.

Constata-se, entretanto, que, para resolver o problema das conseqüências da nulidade rationae personae, deve-se olhar o objeto da nulidade, a fim de circunscrever

\footnotetext{
${ }^{21}$ Do original « Le présent article ne traite que des effets juridiques de la nullité d'un traité. Il ne traite d'aucune question de responsabilité ou de réparation découlant d'actes qui sont la cause de la nullité d'un traité. Le dol et la contrainte, par exemple, peuvent soulever des questions tant de responsabilité et de réparation que de nullité. Mais ces questions sont exclues du champ d'application des présents articles par la règle générale de l'article 69 ». (NATIONS UNIES, 1966, p. 288).
} 
exatamente as conseqüências pessoais de cada declaração de nulidade do tratado. O procedimento é efetuado a partir da Convenção de Viena, que, no artigo 69, distingue dois tipos de causa de nulidade. No primeiro tipo, a Convenção evoca as causas de nulidade que afetam somente o consentimento do Estado interessado (incompetência, erro, dolo, corrupção, uso de força contra o representante de um Estado). Nesses casos, é logico que o tratado multilateral continue válido, mesmo se a obrigação de um de seus signatários for nula. $\mathrm{O}$ segundo tipo refere-se a que as causas invalidam o tratado como um todo (uso de força contra o Estado, ou contravenção ao ius cogens), assim, mesmo que multilateral, o tratado perde a validade.

Conclui-se que o ato declarado nulo promove, por si só, a extensão das conseqüências dessa nulidade, ou seja, é esse ato que determinará o campo pessoal de aplicação da nulidade. Se, por exemplo, esse ato inclui a globalidade dos membros da comunidade internacional, a nulidade terá efeitos erga omnes. Por último, é importante destacar a regra prevista na segunda frase do artigo $69 \S 4^{\circ}$ da Convenção de Viena, segundo a qual as disposições do artigo 69 se aplicam nas relações entre as partes com vício de consentimento e as outras partes do tratado.

\subsection{A divisibilidade das conseqüências da nulidade}

No que se refere à dimensão material das conseqüências da nulidade, é relevante destacar duas asserções importantes. Em primeiro lugar, o princípio da nulidade deve atingir a integralidade das disposições do tratado. Essa indivisibilidade provém do princípio geral do respeito da integridade do tratado, previsto no artigo 44 da Convenção de Viena. ${ }^{22}$. Entretanto, todos os tratados não constituem totalidade solidária. Às vezes, as cláusulas são separáveis porque são independentes umas das outras.

Essa concepção está de acordo com o parágrafo $§ 4^{\circ}$ do artigo 44 da Convenção de Viena, segundo o qual: "Nos casos previstos nos artigos 49 e 50, o Estado que tem o direito de alegar o dolo ou a corrupção pode fazê-lo em relação à totalidade do tratado ou, nos

\footnotetext{
22 Segundo o artigo $44 \S 2$ da Convenção de Viena, “Uma causa de nulidade, de extinção, de retirada de uma das partes ou de suspensão de execução de um tratado, reconhecida na presente Convenção, só pode ser alegada em relação à totalidade do tratado, salvo nas condições previstas nos parágrafos seguintes ou no artigo 60”.
} 
termos do parágrafo $3^{\circ}$, somente às determinadas cláusulas”. A divisibilidade, nesses casos, torna-se facultativa.

A faculdade de dividir as conseqüências, como bem indica a CDI nos trabalhos preparatórios da Convenção de Viena, ${ }^{23}$ é justificada pelo fato de que uma disposição de um tratado pode ser suprimida ou suspensa, sem necessariamente transtornar o equilíbrio dos direitos e das obrigações estabelecidos pelas outras disposições do tratado. A fundamentação dessa argumentação encontra-se nas decisões da Corte Permanente de Justiça Internacional, nos casos Zonas Francas e Wimbledon ${ }^{24}$.

Em segundo lugar, constata-se que as conseqüências da nulidade de um tratado podem estender-se a outros atos além dos especificamente afetados pela nulidade. Ou seja, pode-se efetuar a construção abstrata de relações hierárquicas existentes entre os diversos atos que conduzem a invalidações logicamente necessárias. Verhoeven (1980, p. 98) afirma, entretando, que essa extensão é difícil ser utilizada na prática, porque é difícil estabelecer critérios de conexão entre os atos jurídicos. Retorna-se, então, ao início deste estudo, que indica a dificuldade de transpor ao direito internacional os critérios próprios do direito interno.

\section{CONCLUSÃo}

Apesar de ser, ainda hoje, uma matéria extremamente téorica, que obteve única aplicação em épocas de guerra, é possível retirar algumas conclusões sobre as conseqüências da nulidade dos tratados em direito internacional público. Em primeiro lugar, indica-se que a conseqüência direta da declaração de nulidade de um tratado internacional é a ausência de força jurídica. Além disso, mesmo que o texto da Convenção de Viena de 1969 não disponha sobre o tema, conforme os trabalhos preparatórios dessa Convenção, conclui-se que a declaração de nulidade possui conseqüências retroativas. O retorno ao statuo quo, nesse sentido, é integral.

A questão fundamental sobre o assunto é a de esclarecer quais são as conseqüências dos atos realizados com base no tratado inicial declarado nulo. Três dimensões

\footnotetext{
${ }^{23}$ NATIONS UNIES. Annuaire de la Commission du Droit International. 1963. Vol. II. p. 221.

${ }^{24}$ Affaire des Zones Franches, C.P.J.I., série A/B, n46, p. 140; l'affaire du Wimbledom, C.P.J.I., série A, n¹, p. 24.
} 
precisam ser consideradas para responder a esta questão. A dimensão rationae temporis indica a regra de retroatividade das conseqüências da nulidade, que pode ser atenuada pela nulidade ex nunc prevista no $\S 2^{\circ}$ do artigo 69. É legítimo atenuar o rigor da sanção retroativa, a fim de reduzir as perturbações criadas, pelo retorno dos atos realizados a partir do tratado, ao ponto inicial. Já a dimensão rationae personae demonstra que é o tratado declarado nulo que circunscreve por si só a extensão das conseqüências da nulidade sob os atos realizados a partir do tratado inicial. Em último lugar, a dimensão rationae materiae indica que, se há um princípio geral de respeito da integridade do tratado, previsto no artigo 44 da Convenção de Viena, as cláusulas de um tratado podem separar-se porque são independentes umas das outras. Assim, o parágrafo $4^{\circ}$ do artigo 44 da Convenção de Viena propõe a divisibilidade facultativa das conseqüências da nulidade nos casos de dolo ou corrupção.

\section{REFERÊNCIAS}

AGO, R. Le droit des traités à la lumière de la Convention de Vienne: introduction. R.C.A.D.I., 1971 (III), p. 303-339.

BINDSCHEDLER-ROBERT, D. De la rétroactivité en droit international public. In: Recueil d'études de droit international en hommage à Paul Guggenheim, Université de Genève, Institut universitaire des háutes études internationales, Paris: Pedone, 1968, p. 184-200.

BRETTON, Ph. Les négociations germano-tchécoslovaques sur l'accord de Munich du 29 septembre 1938. In: Annuaire français du droit international. 1973.

CAHIER, Ph. Les caractéristiques de la nullité en droit international et tout particulièrement dans la Convention de Vienne sur le droit des traités. R.G.D.I.P. [S.l.: s.n.], 1972. p. 685-691.

CAPOTORTI, F. Cours général de droit international public. R.C.A.D.I., [S.l.: s.n.], 1994 (IV), n 248, p.175-200.

COMBACAU, J. Logique de la validité contre logique de l'opposabilité dans la Convention de vienne sur le droit des traités. In : VIRALLY (M.) (Mélanges). Le droit international au service de la paix, de la justice et du développement, Paris: Pedone, 1991. p.195-203.

ELIAS, T-O. Problems concerning the validity of treaties. R.C.A.D.I, [S.l.: s.n.], 1971 (III), n¹34, p. 334-416.

NATIONS UNIES. Annuaire de la Commission du droit international. [S.l.: s.n.], 1963, II, p.98-99 e 220-226. 
p.258-289.

Annuaire de la Commission du droit international. [S.l.: s.n.]1966, I, p.1-20 et II,

PELLET, A.; DAILLIER, P. Droit International Public. Paris. LGDJ, 2001.

ROSENNE, S. The law of the treaties: a guide to the legislative history of the Vienna Convention. Leiden: Oceana Publications, 1970. p. 358-359.

SALMON, J. (dir.). Dictionnaire de droit international public. Bruxelles: Bruylant, 2001.

VERHOEVEN, J. Les nullités du droit des gens. In: Droit international 1: Institut des hautes études internationales de Paris : cours et travaux. Paris: Pedone, 1979/1980. p. 88-105.

WEIL, P. Le droit international en quête de son identité. In: Cours général de droit international public. R.C.A.D.I, 1992 (VI), nº 237, p. 313-327.

\section{JURISPRUDÊNCIA}

Différend territorial (Jamahiriya arabe libienne c. Tchád), 1994, Recueil C.I.J..

Affaire Ambatielos, 1952, Recueil C.I.J.

Concessions Mavrommatis en Palestine (Grèce c. Royaume-Uni), 1923, Recueil C.P.I.J., série $\mathrm{A}, \mathrm{n}^{\circ} 2$.

Zones franches de la Háute Savoie et du Pays de Gex (France c. Suisse), 1929, C.P.J.I., série $\mathrm{A} / \mathrm{B}, \mathrm{n}^{\circ} 46$.

Vapeur Wimbledom (Royaume-Uni, France, Italie, Japon c. Empire allemand), 1923, Recueil C.P.J.I., série $A, n^{\circ} 1$.

Prismas: Direito, Políticas Públicas e Mundialização

http://www.mestrado.uniceub.br/revistamestrado/

Artigo recebido em 15/03/2006 e aceito para publicação em 13/04/2006

A revista Prismas: Direito, Políticas Públicas e Mundialização destina-se à publicação de artigos relacionados com a área jurídica, tem o propósito de difundir as reflexões dos pesquisadores, docentes, discentes, profissionais e estudantes da área de Ciências Jurídicas.

Os artigos são avaliados mediante processo de revisão por pares e deverão contemplar as reflexões que dizem respeito ao estudo do Direito, das Relações Internacionais e das Políticas Públicas. 